\title{
Quer brincar de charadas? Possibilidades de uso do jogo CharadesApp para ampliaçáo e prática lexical de repertórios em língua inglesa
}

\author{
Barbra Sabota ${ }^{1}$
}

Sarah da Silva Araújo ${ }^{2}$

\section{Resumo}

A presença das Tecnologias Digitais de Informação e Comunicação em nossa sociedade tem nos impelido a refletir sobre seu uso em situaçóes que envolvem o contexto educacional. Neste estudo bibliográfico documental discorremos sobre a possibilidade de ampliação lexical e prática lúdica de repertórios léxico-semânticos em Língua Inglesa por meio do jogo interativo gratuito CharadesApp. $\mathrm{Na}$ análise do aplicativo com esta finalidade, recorremos à tabela proposta por SABOTA e PEREIRA (2017) elaborada para análise qualitativa de ferramentas digitais. Concluímos que há substantivas oportunidades de uso do aplicativo para aprendizagem e prática do idioma de modo lúdico, havendo, assim, indicação para seu uso como ferramenta educativa complementar.

Palavras-chave: ensino-aprendizagem; língua inglesa; aplicativo CharadesApp.

\section{Do you want to play charades? Possibilities for using the game CharadesApp to expand and practice the English lexicon}

\section{Abstract \\ The presence of Digital Information and Communication Technologies in our society has impelled us to reflect on their use in situations involving the educational context. In this documentary bibliographical study, we discuss the possibility of lexical expansion and ludic practice of lexical-semantic repertoires in English Language through the use of the free application Charades. In the application analysis, we use the table proposed by SABOTA and PEREIRA (2017) prepared for qualitative analysis of digital tools. We conclude that there are substantial opportunities to use the application to learn and practice the language in a playful way, thus indicating its use as a complementary educational tool.}

Keywords: teaching-learning; English language, application Charades.

1 Doutora em Letras e Linguística pela Universidade Federal de Goiás (UFG). Professora na Universidade Estadual de Goiás (UEG), no curso de Letras e no Mestrado Interdisciplinar em Educação, Linguagens e Tecnologias (PPG-IELT - UEG), Campus Anápolis/GO. E-mail: barbrasabota@ gmail.com.

2 Mestra em Educação, Linguagens e Tecnologias pela Universidade Estadual de Goiás (PPG-IELT UEG). Campus Anápolis/GO. E-mail: sarah.pacto.go@gmail.com. 


\section{Introduçáo}

Nos últimos anos, temos testemunhado o advento das Tecnologias Digitais que têm rapidamente ocupado diversos espaços sociais e agregado usuários em torno de transaçóes comerciais, encontros sociais e profissionais, aplicativos de mobilidade, realização de serviços bancários, entretenimento, entre outros (KENSKI, 2013). Segundo a autora, seria inviável que a educação se mantivesse fora desse cenário e, como Kenski (2013) observa, cursos à distância e materiais complementares voltados para engajar os alunos com o uso de tecnologias digitais já são uma realidade. Na linguística aplicada, autores como Araújo e Leffa (2016) e Paiva (2001), por exemplo, têm se dedicado a organizar coletâneas que busquem entender como as redes sociais e diversos sites e/ou aplicativos têm participado do processo de ensinar e aprender línguas. Na linguística aplicada crítica, Rojo (2013) e Coscarelli (2012) têm buscado discutir o tema pelo viés dos letramentos e da multimodalidade. Em ambos os cenários, estudos apontam que, antes de inserir as tecnologias digitais de informação e comunicação (doravante TDIC) em contextos educacionais, é importante refletir com que finalidade tal inserção tem sido feita. Ou seja, para além de acompanhar o avanço tecnológico, cabe perceber de que modo o uso de TDIC corrobora para que os aprendizes estejam aptos a acessar diversos conteúdos, entender e criar sentidos, por fim, inovar usando recursos de seu tempo (ROJO, 2013).

Nos dedicamos, neste artigo, a investigar as possibilidades de uso de um jogo disponível para dispositivos móveis (celulares ou tablets), o CharadesApp, para situações de ampliação lexical de repertórios em língua inglesa, em contexto educacional. Em nossa análise bibliográfico-documental, exploramos as potencialidades do aplicativo nos aspectos técnicos, teóricos e práticos, como recomendado por Sabota e Pereira (2017), com ênfase nas contribuiçóes do aplicativo para aulas em que a multimodalidade seja uma preocupação. Ao final do texto, traçamos alguns comentários específicos sobre a multimodalidade e como ela pode integrar as aulas de línguas com o auxílio das TDIC. 
Breves consideraçóes sobre as TDIC e o cenário atual de ensino-aprendizagem de inglês

Diversas são as causas que levaram a língua inglesa a ter grande expansão no mundo, como aponta Rajagopalan (2005). Seja em decorrência do projeto de expansáo colonizadora, da globalização como um fenômeno mundial acirrado pelo uso das tecnologias, ou pela ampla divulgação do conhecimento científico pela internet, o fato é que o inglês ocupa atualmente um local de privilégio. Aprender outra língua pode nos permitir participar efetivamente de contextos maiores e ampliar os horizontes, acessar e compartilhar novas fontes de informação, entretenimento ou materiais que precisamos, valorizamos ou gostamos (USHIODA, 2012).

Sabota e Silva (2016) apontam que as tecnologias digitais podem representar um importante aliado no processo de ensinar e aprender línguas, sobretudo, inglês, como demonstra o estudo dos autores sobre o uso de aplicativos para essa finalidade. Para os autores, o potencial lúdico presente nas ferramentas digitais, evidenciado pelo layout dos aplicativos e pelo modo como atuam na gamificação dos conteúdos de aprendizagem, pode se tornar um grande aliado para fomentar a persistência do público jovem na aprendizagem por meio de aplicativos. Como afirma Yozo (1996), o lúdico simboliza as descobertas dos seres humanos e, por isso, o jogo pode colaborar para que aprendizes internalizem normas, limites e regras de forma descontraída.

Bueno e Sabota (2016), em um estudo sobre como os jogos de RPG on-line podem contribuir para o desenvolvimento do inglês de seus usuários, discutem que, caso haja mediação e açóes intencionais, a aprendizagem desse idioma pode ser facilitada pelo uso de jogos, mesmo que não tenham sido desenhados, a princípio, com essa finalidade. Nesse sentido, embora, em muitos contextos, os jogos e brincadeiras ainda sejam recebidos com preconceito, como se fossem um distrator incômodo e com pouco valor educacional, essa pode ser uma prática profícua quando exercida dentro de um planejamento voltado para fins de aprendizagem (BUENO; SABOTA, 2016).

Sabota e Pereira (2017) dedicaram-se a entender como aplicativos e ferramentas digitais podem ser usados como recursos educacionais e elaboraram uma tabela de avaliaçáo de recursos digitais para ser utilizada por pesquisadores e professores que desejem considerar o potencial didático desses recursos. A tabela proposta pelos pesquisadores (anexo) abrange aspectos técnicos, teóricos e práticos. Cabe ressaltar que não é intenção de Sabota 
e Pereira (2017) separar teoria e prática, e tampouco dicotomizar questóes que são para eles, como afirmado no artigo, indissociáveis e concernentes à práxis docente. A proposta é, tão somente, entender separadamente como cada aspecto do recurso contribui para o processo de educaçáo linguística.

Nesse sentido, nos aspectos técnicos são observadas características de usabilidade e funcionamento do recurso: organização visual (layout e design), gratuidade, acessibilidade, convergência e integração de mídias e suportes, tutorial e tipo de linguagem usada para conversar com o/a usuário/a. Quanto aos aspectos teóricos, são analisados os critérios que fazem com que um determinado recurso seja adequado ao modo de ensinar dos/das docentes. Portanto, os autores sugerem que nos atentemos para a abordagem de ensino e aprendizagem intencionada no desenvolvimento do recurso, haja vista que é importante que os instrumentos de ensino-aprendizagem sejam compatíveis com o modo de os/as docentes desenvolvem sua práxis. Como o aplicativo que ora analisamos não apresenta fins didáticos, mas sim recreacionais, o que fazemos aqui é uma indicação de como aproximar o que ele oferece e pensá-lo a partir de nosso viés de atuação, tal como feito em Sabota e Silva (2016). Nesse sentido, são observadas questôes relativas ao processo de ensino-aprendizagem, tais como interação entre as pessoas e interatividade (com o recurso), oportunidades de construção de saberes e prática de língua(gem) situada, entre outras.

Em termos de aspectos práticos, a tabela propóe entender como o recurso se adequa ao contexto de sala de aula e visa entender a flexibilidade de uso do aplicativo (ou recurso educacional), o engajamento que causa no/a aprendiz com o recurso (incentivos para continuar usando, como por exemplo, estrelas de pontuação e gradações em níveis), e, por fim, se há preocupação com algum retorno que vise expandir a afetividade da relação de ensino-aprendizagem, como pode ser percebido pela oferta de uma avaliação individualizada da experiência do/a aprendiz. Alguns dos itens, propostos da tabela, náo se aplicam ao aplicativo CharadesApp, analisado neste artigo, já que ele é apresentado ao público como um jogo recreacional e não como um recurso educacional. Contudo, por entender que parte do trabalho docente é perceber como algo que está fora da sala de aula pode ser utilizado dentro dela, rompendo as barreiras do lá e cá, nos dedicamos a analisar esse aplicativo. $\mathrm{Na}$ intenção de vê-lo como um todo, trazemos a análise dos aspectos técnicos, teóricos e práticos de modo entrelaçado e não separadamente. 
Neste artigo, lançamos mão dessas categorias da tabela para entender se e em que medida o aplicativo CharadesApp, desenvolvido pela empresa ArtGame Studio, pode ser um recurso didático auxiliar no processo de ensino-aprendizagem de inglês. Por ser disponível em três idiomas - português, inglês e espanhol - o jogo pode atender aprendizes de língua materna e ou adicional/estrangeira. No entanto, dedicamo-nos a refletir sobre a aprendizagem de inglês, por ser esse nosso contexto de atuação.

Por ter um aplicativo como objeto de análise, este estudo se caracteriza como uma pesquisa bibliográfica documental qualitativa. Nos apoiamos nos estudos já realizados por uma das autoras deste texto (SABOTA; SILVA, 2016; BUENO; SABOTA, 2016) para seguir entendendo os aplicativos para dispositivos móveis como um documento que registra o momento histórico e social de produção cultural em que está inserido. Para as autoras Sá Silva et al. (2009), a pesquisa documental qualitativa pode auxiliar no entendimento do valor de documentos como objetos culturais para o aprimoramento das práticas educativas, como é foco deste estudo.

\section{Conhecendo melhor o aplicativo CharadesApp}

O jogo CharadesApp é disponibilizado gratuitamente ${ }^{3}$ em lojas de aplicativos para dispositivos móveis, como celulares e tablets com sistema IOS e Android. O jogo é descrito por seus desenvolvedores, ArtGame studios (APKpure, 2019), ${ }^{4}$ como "um jogo de mímicas e advinhaçóes de palavras para jogar com amigos". Ao baixar o jogo em seu dipositivo, um tutorial em portugês é disponibilizado explicando como interagir. É possível, na aba de configuraçóes, selecionar a idade para uma exepriência mais personalizada do jogo. Além disso, podemos selecionar o idioma para prática em duas outras línguas, espanhol e inglês.

3 Embora haja opções de compra dentro do jogo, é possível divertir-se com a versão gratuita.

4 Disponível em: https://apkpure.com/br/charadesapp-what-am-i-guessing-and mimics/net. artgamestudio. charadesapp. Acesso em: 04 dez. 2019. 
Figura 1 - Conhecendo o aplicativo CharadesApp

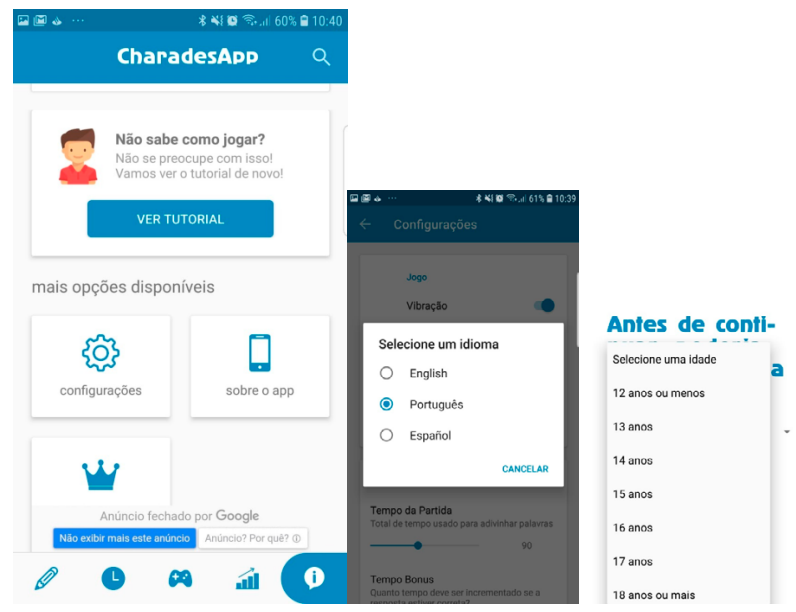

Fonte: foto (print) da tela inicial do jogo disponível no próprio aplicativo Charades $A p p^{5}$

A apresentação visual da tela de jogo (layout $)^{6}$ é simples e fácil de ser lida. Uma tela com cores fortes (variando entre azul, verde, vermelho e amarelo) e chamativas, com palavras (ou imagens, no tema memes ou infantil) grafadas em fontes simples, grandes, centralizadas na tela. $\mathrm{O}$ azul indica que uma partida está em andamento, o amarelo traz um alerta aos/às jogadores/ as, como mostra a figura 2 , e as cores verde e vermelha são usadas para indicar como está indo o progresso no jogo (verde indica acertos e vermelhos indicam erros, em alusão às cores de um semáforo). $\mathrm{Na}$ parte superior da tela, na figura 3, temos a indicaçáo do tempo restante da partida, em contagem regressiva, um ícone para pausar à direita e um ícone, à esquerda, para voltar à tela de escolha de temas. Em todos os casos, a cor escolhida para a fonte é a branca, trazendo destaque e luminosidade para a informação principal, como vemos a seguir.

5 A fim de reduzir o número de notas de rodapé com as traduções das figuras ilustrativas utilizadas ao longo do artigo, optamos por trazer os prints (as fotos) de telas em português. Contudo, lembramos que, como explicado na figura 1, é possível selecionar o idioma e ver todas as telas em português, espanhol ou inglês.

6 O layout não é somente a forma como um aplicativo se apresenta ao usuário, mas é, também, um recurso de construção de sentido (SIGNORINI; CAVALCANTI, 2010). 
Figuras 2 e 3 - Conhecendo o aplicativo CharadesApp. Em amarelo um alerta (Figura 2) e em azul (figura 3) uma partida em andamento sob o tema frutas

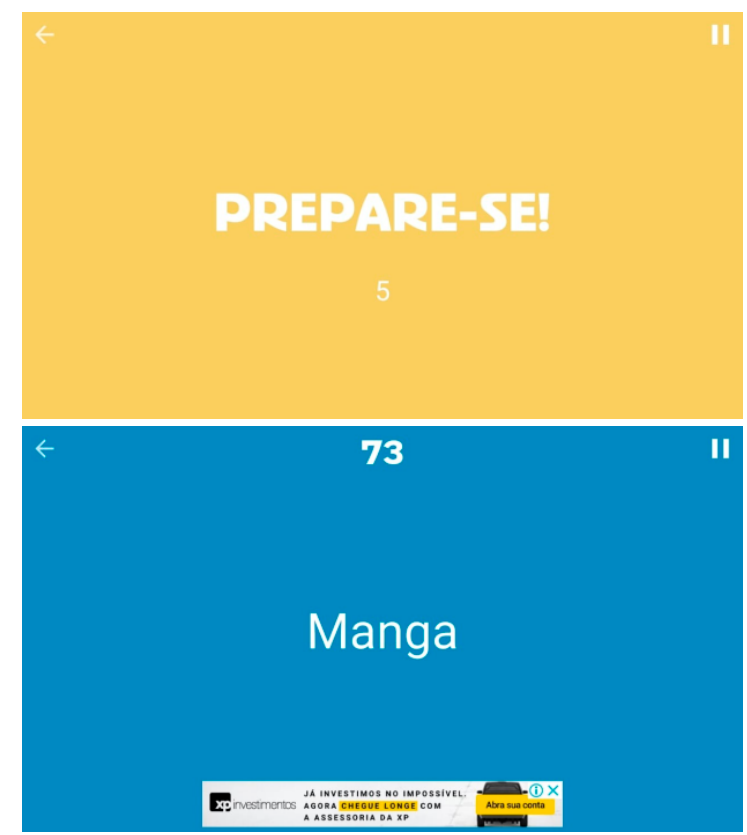

Fonte: fotos (print) da tela do jogo, disponível no próprio aplicativo CharadesApp.

Após o jogo ser baixado, a internet só é necessária para fazer atualizaçóes na versão do aplicativo, o que possibilita que aprendizes utilizem o jogo em sala de aula, sem estarem conectados. A nosso ver, isso pode trazer algumas vantagens. A primeira é que, por não estar on-line, o acesso que o/a aluno/a tem ao dipsositivo náo é interrompido por outros aplicativos e notificaçóes que atuem como distratores no momento da atividade. Outro ponto favorável é que em localidades onde não haja fácil acesso à rede de computadores, o jogo continua funcionando normalmente. Segundo Kenski (2013), a instabilidade das conexóes com a internet em nosso país tem sido um empecilho ao amplo uso das tecnologias digitais em contextos educacionais. Em escolas e instituiçôes de ensino cujo acesso à internet seja vetado, esse é um bom recurso para que não seja necessário abrir mão do uso de recursos digitais, que tendem a ter bom apelo entre os jovens (KENSKI, 2013). 
Devido à simplicidade do design e a facilidade do jogo, ele torna-se uma estratégia importante para ser explorada por professores/as e alunos/ as em diferentes ocasióes e por turmas em diferentes níveis de repertórios linguísticos. Para uso em sala de aula, o/a docente pode se valer da simplicidade de vocabulário e da multimodalidade para fazer com que os/as alunos/ as aprendam a jogar em inglês (na língua estrangeira/adicional) e ter uma oprtunidade a mais de prática do idioma e da ampliação de seus letramentos. Afinal, ler e entender instruçóes é uma habilidade relevante para aprendizes, não apenas de idiomas, mas de um modo geral. Afinal, são muitas as ocasiôes em que temos de seguir comandos e efetuar açóes, como em outros tutoriais, receitas, prescriçóes médicas, entre outros.

Contudo, caso este não seja o foco almejado pelo/a docente, é possível ler as instruçóes no tutorial em português, como ilustrado no centro da figura 1, e seguir as imagens para entender como o jogo funciona: seleciona-se uma categoria de palavras e/ou charadas; seleciona-se o tempo para o desafio; coloca-se o dispositivo contra a testa; e os/as colegas de jogo auxiliam a descobrir qual é a charada. Eles/elas dáo dicas por meio de explicaçóes (em inglês), mímicas e gestos até que o o/a jogador/a advinhe a palavra/charada. Para sinalizar que advinhou, o/a jogador/a movimenta o dispositivo para cima (caso acerte), ou para baixo (caso não descubra). Após a movimentação do dispositivo, uma outra palavra/charada é apresentada até que o tempo limite seja alcançado.

Os jogos, em geral, permitem ao usuário fazer escolhas que vão influenciar as diversas narrativas. Isso significa que jogadores diferentes podem seguir diferentes caminhos, ou um mesmo jogador pode escolher caminhos diferentes todas as vezes que joga, mesmo que o resultado final não varie (ZACHI, 2017), já que o objetivo final do jogo é o mesmo, ou seja, acertar a palavra/charada que aparece na tela. Isso pode representar, para os/as aprendizes, mais oportunidades de escolha, ao selecionar categorias ou decidir se avança ou se detém por mais tempo em uma charada, por exemplo. Pode também implicar vivências e práticas simultâneas e diferenciadas, possibilitando que a própria atividade de escolha de categoria seja um momento de decisão e escolhas autônomas dentro de cada grupo formado na sala de aula.

O jogo apresenta 180 temas diversificados que abrangem públicos de interesses e idades distintas. No entanto, apenas 48 são disponíveis na versão grátis. Apesar de representar menos da metade dos itens, ainda assim há charadas sortidas o suficiente para garantir bons momentos lúdicos de 
troca comunicativa. Alguns dos temas gratuitos que destacamos, à guisa de ilustração dessa variedade são: ação (verbos), comidas, animais, músicas, memes, seriados, filmes, profissóes, capitais do mundo, dentre outros.

Durante o jogo, o próprio aplicativo vai sugerindo dicas para o modo como a palavra pode ser descrita, como por exemplo na imagem abaixo, que traz sugestôes para que os colegas façam a mímica de um filme a ser adivinhado.

Figura 4 - Exemplo de filme a ser advinhado na rodada

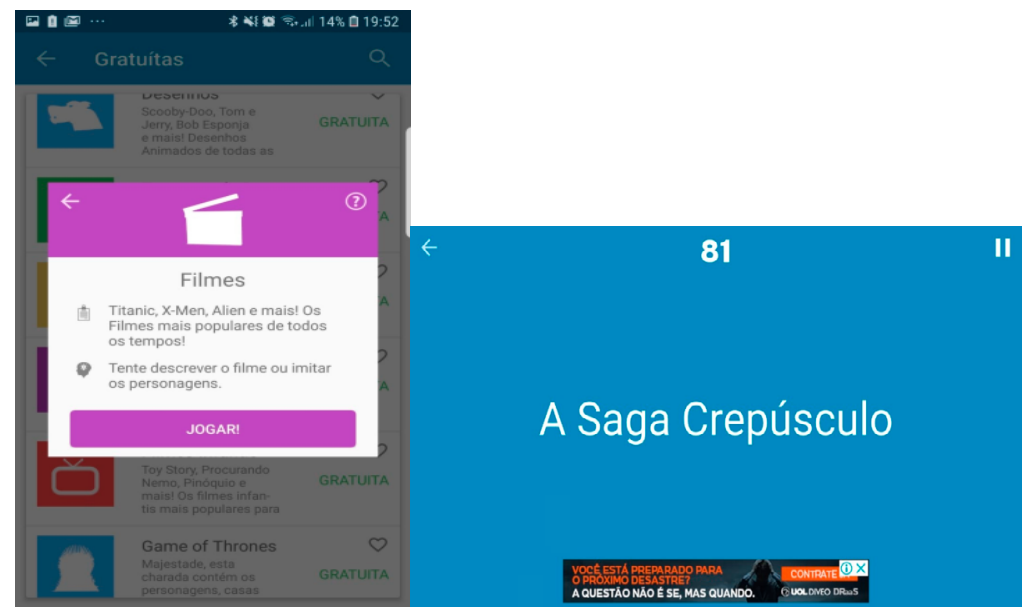

Fonte: foto (print) da tela do jogo, disponível no próprio aplicativo CharadesApp sob o tema movies (filmes)

$\mathrm{Na}$ figura 4, vemos à esquerda o nome da categoria e uma breve descrição do que é encontrado nesse tema. Esse é um exemplo de como as categorias são introduzidas. À direita, temos o nome do filme que os/as jogadores/as que teráo de auxiliar o/a jogador/a que segura o dispositivo a adivinhar. Nesse momento do jogo, é esperado que façam mímicas e/ou construam suas explicaçóes sobre o filme sem dizer o nome dele. Richard-Amato (1989) já alertava sobre a importância do uso de jogos na aprendizagem comunicativa. Para a autora, essas técnicas servem como elemento de motivação e, além de promoverem a interação entre os aprendizes, elas ajudam a dar mais dinâmica às aulas, engajando os/as alunos/as em atividades nas quais se tente preencher uma lacuna de informação, ou nesse caso, uma advinhação. Prescher (2010) soma a essa ideia da comunicação, a possibilidade de construção de novas estratégias e novos saberes ao tentar desem- 
penhar um papel em uma atividade lúdica. Zachi (2017), que estuda jogos em um contexto de letramento, aponta para como esses recursos auxiliam aprendizes a lidar com desafios da linguagem e como a imprevisibilidade da reação dos/das interagentes faz com que possa ocorrer ampla exploração dos repertórios linguísticos dos/as aprendizes.

Como meio de engajar jogadores, o CharadesApp premia bons resultados para que possam ascender a outros níveis dentro de um tema/categoria. Além dessa pontuação, ao final de cada rodada, o jogo lança confetes coloridos que caem da tela representando uma celebração de nosso progresso no jogo, como vemos na figura 5.

Figura 5 - Exemplo de feedback do progresso no jogo

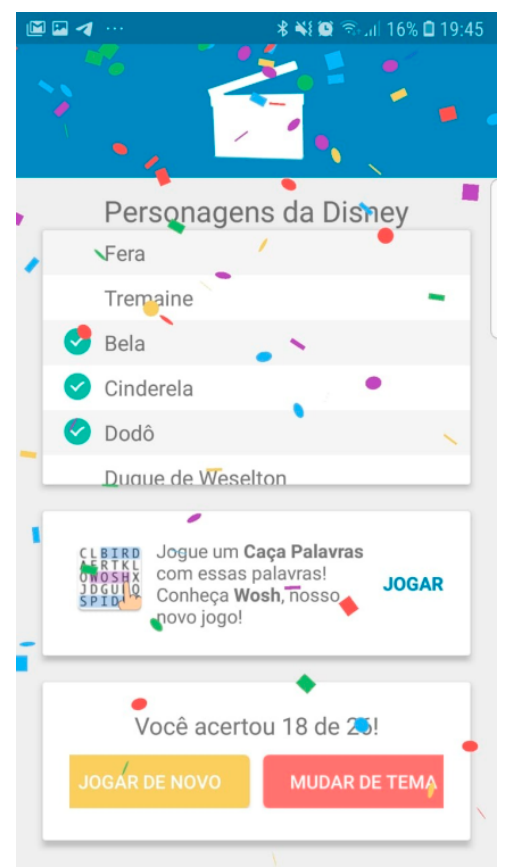

Fonte: foto (print) da tela do jogo, disponível no próprio aplicativo CharadesApp.

Ao final da tela, temos um resultado que nos informa quanto foi acertado em cada categoria e nos mostra o convite a repetir a rodada ou mudar de tema. A curiosidade aliada ao desafio faz com que haja o interesse em voltar para o jogo e/ou continuar tentando. 
Além disso, a possibilidade de interagir com os/as colegas em um outro idioma, sob uma proposta lúdica, pode fazer a diferença em sala de aula. Por ser um jogo simples e envolvente, não é necessário muito tempo de aula e nem grande preparo prévio. O CharadesApp torna-se uma alternativa viável para revisar conteúdos lexicais, encerrando ou iniciando uma aula de modo lúdico.

Considerando que o jogo será realizado em inglês, é possível aventar que os/as alunos/as estarão em turnos, tentando explicar aos/às colegas quais são as charadas propostas na tela do aplicativo. Os meios para a explicação podem ser verbais, sonoros e gestuais, como consta da regra de um jogo de charadas. Ao seguir essas regras, os/as aprendizes são desafiados a explorar seus repertórios para construir sentidos e interagir. Logo, é possível entender que conhecimentos prévios serão requisitados nesse momento e que a mediação central sairá da voz do/da docente para os/às alunos/as. Não é possível prever, como já mencionamos, que léxico será requisitado, contudo, projetamos que os/as alunos/as, ao se envolverem no jogo, usem palavras, sons e gestos que, quando compartilhados, ampliem o que os/as colegas já sabem. Isso, a partir de uma abordagem sociointeracionista (VYGOTSKY, 1998), pode evidenciar uma aprendizagem que derive de uma relação interpessoal, horizontalizada e, colaborativamente, atue no processo de ensino-aprendizagem. A cada vez que um vocábulo é interpretado no jogo, novas possibilidades de realizaçóes linguísticas são favorecidas e a aprendizagem pode ocorrer a cada nova interaçáo com o outro e com o jogo, em si, denotando uma situação de interação (com pessoas) e interatividade (com o recurso), como apontado por Sabota e Pereira (2017). Com a variedade dos temas - de comidas, açóes e esportes à filmes, memes e músicas - muitos contextos e repertórios são compartilhados, ampliando os saberes discentes e permitindo que os/as docentes conheçam melhor seus aprendizes. A possibilidade de fazer vários temas entrarem nas aulas também contribui para o debate sobre as escolhas discentes, sendo os temas pretexto para futuros debates, contemplando interesses dos/das aprendizes e trazendo mais engajamento para as aulas. A circulação de novos saberes no espaço educacional pode oxigenar os diálogos, trazendo da margem para o centro o interesse dos discentes, o que pode favorecer que novas formas de pensar sejam construídas e novos debates sejam provocados (ZACHI, 2017).

Ao propor o jogo, o/a docente pode optar entre deixar que os/as alunos/as naveguem livremente pela aba de temas e, em pequenos grupos, 
decidam sobre o que querem jogar, de acordo com o interesse pessoal. Esse tipo de autonomia pode auxiliar no processo de aprender a fazer e negociar escolhas de modo colaborativo e respeitoso, o que pode incluir aprender a argumentar e conviver com o dissenso (MENEZES DE SOUZA, 2011).

O jogo marca uma pontuação por partida. Tal marcação pode servir de referência para que os grupos aprendam a se superar, acertando mais charadas a cada rodada, ou pode-se expandir a competiçáo para a sala de aula, aferindo quais grupos acertaram mais. Nesse caso, cabe salientar que seria relevante conversar com os participantes sobre nosso papel em competiçóes e que desdobramentos essas disputas podem ter. Essa pode ser uma oportunidade para conversar sobre nossa sociedade atual e como devemos aprender a ganhar e a perder, aspecto salientado por Bauman (2011) como deficitário na juventude atual. Para o autor, por estarem acostumados a ter muito e com facilidade, nossos jovens não têm desenvolvido resiliência, persistência e tolerância, características consideradas pelo sociólogo como fundamentais para o avanço da ciência, bem como para o respeito aos valores que asseguram os marcos civilizatórios (BAUMAN, 2011).

Como o aplicativo não disponibiliza nenhum tipo de feedback para o/a aluno/a quanto ao seu desempenho linguístico, o avanço no jogo é medido pela pontuação no acerto das charadas propostas. Se considerarmos que o aplicativo é recreacional e não educativo, é fácil entender que isso não chega a ser uma falha dos desenvolvedores. No entanto, para uso em salas de aula, seria apropriado que o/a professor/a, anteriormente ao jogo, tematizasse o seu conteúdo, ampliando a possibilidade de acerto entre os/as participantes. Ademais, após as partidas, sugerimos que estratégias de ensino com o foco de revisáo e/ou retençáo de conteúdo sejam desenvolvidas a fim de favorecer que os itens recém aprendidos/revisitados no jogo fossem apropriados pelos/as alunos/as de modo a integrar seu repertório linguístico em inglês. Ou seja, o jogo sozinho não garante a aprendizagem. Mas podemos afirmar que algum elemento isolado em uma aula de línguas tenha essa característica? Acreditamos que não, daí a relevância de planejamento das açóes de ensino no processo de aprendizagem.

\section{Algumas consideraçóes sobre a multimodalidade no CharadesApp}

Segundo Dionísio (2011), a multimodalidade pode ser definida como modos diversos de representação de conteúdo utilizados na construção lin- 
guística de uma dada mensagem, assim como palavras, imagens, cores, formatos, marcas, gestos, padrôes de entonação, olhares etc. Essas formas de representação apresentam-se de modo concomitante e complementar desde que auxiliem na composição de mensagens previstas pelo texto.

Nessa perspectiva, Coscarelli (2012) afirma que é preciso repensar o sentido da palavra 'texto' usada hoje em dia, para entendê-lo como um objeto complexo e constituído de várias semioses, dentre elas, a música, o movimento e a imagem. O texto passa a ser assim entendido como uma teia de sentidos diversos, contidos em sons, imagens e palavras escritas, por assim dizer, que, ao serem tecidos juntos, proporcionam a leitura.

Vários elementos são utilizados na construção do sentido e devem ser acionados durante a compreensão textual (SABOTA, 2017). Se utilizarmos esse conceito de texto para expandir nossa análise do aplicativo, é possível perceber que, no texto do jogo, recursos como cores, tamanhos de fonte, números e vibraçóes são utilizados para atrair a atenção dos/as jogadores/as e para construir interativamente o jogo. Ao jogar, outros aspectos da multimodalidade como mímicas, sons, gestos e sentenças verbalizadas oralmente juntam-se aos primeiros elementos, garantindo a jogabilidade e boas risadas entre os participantes.

Para Dionísio (2011), todos esses distintos modos de construir um texto acarretam modificaçóes substanciais na forma como as pessoas elaboram sentido e significação, transcendendo, dessa maneira, a primazia dada à palavra. Nas figuras trazidas ao longo do artigo, mostramos como isso se dá no aplicativo CharadesApp.

Salientamos que esse jogo já existia antes desse recurso digital e que ele pode continuar a ser jogado com cartóes de papel manuscritos. No entanto, entendemos que a facilidade de propor temas distintos sem gerar o trabalho de produzir os cartóes pode poupar um valioso tempo ao/à professor/a. Como afirma Kenski (2013) e Bauman (2011), nesse século, o ritmo acelerado da vida (pós/líquido) moderna tem acarretado alteraçôes nas rotinas de todos/as e isso inclui os/as docentes que, em meio a tantas atribuiçóes de seu trabalho, possui a responsabilidade de preparar materiais complementares para favorecer o engajamento de suas turmas com os temas das aulas. Não estamos querendo dizer que o aplicativo, ou qualquer outro, represente uma solução para a atribulada vida de professor/a, porém, contar com o apoio de um material que tem boa aceitação entre discentes é uma considerável ajuda. 
Apesar da multimodalidade não se restringir aos textos relativos a ambientes tecnológicos, segundo Mayer (2002), ela se popularizou juntamente com a tecnologia computacional, que permitiu uma explosão na disponibilidade de modos de apresentaçáo visual de materiais e que, por consequência, causaram uma revolução no cenário da comunicação. Até pouco tempo atrás, os recursos visuais e tipográficos eram mais comumente utilizados para ênfases e ilustrações.

Com o advento dos computadores, mais textos podiam ser produzidos (com certa facilidade) utilizando-se os meios digitais, daí os elementos passaram a se organizar em complementaridade de sentido com mais frequência. No entanto, infelizmente, nem sempre a multimodalidade é explorada em sala de aula. Permanecemos privilegiando, em nossas aulas, leituras lineares e sem muitas possibilidades de variaçáo no sentido construído (SABOTA, 2017). A entrada de recursos na escola, como o aplicativo trabalhado neste artigo, pode abrir portas para alertar sobre a relevância da expansão do conceito de texto e de leitura. É importante entender que as crianças e jovens que frequentam a escola no século XXI já estão inseridos em contextos multimodais, como os da televisão, dos computadores e dos dispositivos móveis conectados à internet, e, por isso, quando chegam à escola, esperam mais de uma aula de línguas do que atividades tradicionais de memorização de palavras e regras. Como também afirma Moran (2007), a escola negligencia o poder de gerar significados de uma imagem e, com isso, subutiliza-se também a dramatização, a paráfrase, o jogo, os vídeos e outros textos.

Nesse contexto, levar a multimodalidade para sala pode contribuir para que a aprendizagem seja realizada de forma mais relevante e prazerosa, já que as múltiplas formas de construir sentidos em um texto multimodal proporcionam ludicidade e exploração da criatividade e imaginação durante a compreensão de um texto dinâmico - nesse caso, o jogo.

\section{Consideraçóes finais}

Nos dias atuais, como discutido em alguns pontos deste artigo, tem sido difícil pensar uma instância da sociedade sem a interferência das tecnologias digitais. O modo como convivemos com ela pode ser mais ou menos frequente, inclusivo ou harmônico, contudo, ela se faz presente em diferentes contextos (não apenas em zonas urbanas, mas estendendo-se para a 
zona rural, o sertão e tantos rincóes de nosso país). Não nos compete, neste texto, debater sobre a globalização e seus pontos positivos e negativos. Essa é uma discussão longa e cuidadosa que vem sendo feita dentro da linguística aplicada crítica, como aponta Menezes de Souza (2011). Não pretendemos ingenuamente apresentar as tecnologias digitais, representadas pelo recurso ora selecionado, como uma panaceia em contexto educacional. Acreditamos ter feito ponderaçôes sobre como o CharadesApp pode ser usado como um dentre tantos outros meios de auxiliar os/as alunos/as a se interessarem pela aprendizagem e prática do idioma. Reiteramos que o modo como esses recursos digitais integram a sala de aula e o espaço que eles ocupam nas aulas cabe tão somente ao/à professor/a definir. De igual maneira, a abordagem para tratar das possibilidades do recurso em sala de aula é uma decisão que cabe ao/à docente ao pensar sobre sua práxis e, sobretudo, nas necessidades de seus alunos e alunas. Nossa intenção, neste artigo, foi dedicar um tempo para aplicar nossos esforços no entendimento sobre como o aplicativo pode ser inserido em aulas de inglês (ou de outras línguas, como já assinalado).

Percebemos, na escrita deste artigo, uma oportunidade de contribuir para a formação docente e para a compreensão que se tem atualmente sobre o uso de jogos e aplicativos em aulas de idiomas. Consideramos que a análise feita do CharadesAPD pode ser relevante para que professores/as considerem aspectos importantes do processo de ensino-aprendizagem ao escolher seu material de apoio complementar e/ou suplementar. Esperamos que as consideraçóes sobre o aplicativo em questão instiguem os/as docentes a refletirem sobre outros jogos e recursos educacionais que adentram nossas salas de aula e/ou que podem vir a ser utilizados nesse cenário, ainda que não tenham sido desenvolvidos com essa finalidade.

\section{Referências}

ARAÚJO, Júlio; LEFFA, Vilson. Redes Sociais e ensino de línguas: o que temos de aprender? Campinas: Parábola, 2016.

BAUMAN, Zygmunt. 44 cartas do mundo líquido moderno. Rio de Janeiro: Jorge Zahar, 2011.

BUENO, Cláudio Henrique Costa; SABOTA, Barbra. As inferências da aprendizagem colaborativa de línguas estrangeiras por meio de Role Playing Games (RPG): um estudo do Legend Online. In: VII Fórum Internacional 
de Inovação e Criatividade e II Seminário da Rede Internacional de Escolas Criativas, 2016, Goiânia. Anais... do VII Fórum Internacional de Inovação e Criatividade e II Seminário da Rede Internacional de Escolas Criativas. Goiânia: Editora da UFG, 2016. v. 1. p. 495-504. Disponível em: https:// www.cepae.ufg.br/up/80/o/Escolas_Criativas_Parte_II.pdf. Acesso em: 28 mar. 2016.

COSCARELLI, Carla. Hipertextos na teoria e na prática. Belo Horizonte: Autêntica, 2012.

DIONISIO, Ângela Paiva Gêneros Textuais e Multimodalidade. In: KARWOSKI, Acir Mário; GAYDECZKA, Beatriz; BRITO, Karim Sie (org.). Gêneros textuais: reflexóes e ensino. São Paulo: Parábola Editorial, 2011.

KENSKI, Vani Moreira. Tecnologias e tempo docente. Campinas: Papirus, 2013.

MAYER, Richard. E. Multimedialearning. Cambridge, UK: Cambridge University Press, 2002.

MENEZES DE SOUZA, Lynn Mario Trindade. O professor de inglês e os letramentos no século XXI: métodos ou ética? In: JORDÁO, C. M.; MARTINEZ, J. Z.; HALU, R.C. (org.) Formaçâo desformatada - práticas com professores de língua inglesa. Campinas, SP: Pontes Editores, 2011.

MORAN, José Manuel. Desafios na Comunicação Pessoal. São Paulo: Paulinas, 2007.

PRESCHER, Elisabeth. Jogos e atividades para o ensino de Inglês: the book of activities and games. Barueri: DISAL, 2010.

RAJAGOPALAN, Kanavillil. A geopolítica da língua inglesa e seus reflexos no Brasil: por uma política prudente e propositiva. In: RAJAGOPALAN, Kanavillil; LACOSTE, Yves (org.). A geopolitica do Inglês. São Paulo: Parábola Editorial, 2005.

RICHARD-AMATO, Patricia A. Making it happen: interaction in the second language classroom. NY: Longman, 1989.

ROJO, Roxane (org.). Escola conectada: os multiletramentos e as TICs. São Paulo: Parábola, 2013. 
SÁ-SILVA, J. R.; ALMEIDA, C. D.; GUINDANI, J. F. Pesquisa documental: pistas teóricas e metodológicas. Revista Brasileira de História \& Ciências Sociais, n. 1, 2009.

SABOTA, Barbra. Leitura e compreensão textual. In: FIGUEIREDO, Francisco J. Q. de. Formação de professores de línguas estrangeiras. Goiânia: Editora da UFG, 2017. p. 125-150.

SABOTA, Barbra; SILVA, Hermindo Elizeu da. "Então, você quer aprender a falar inglês” Via Litterae. Anápolis. v. 8, n. 2. p. 283-301 • jul./dez. 2016. Disponível em: http://www.revista.ueg.br/index.php/vialitterae/.

SABOTA, Barbra; PEREIRA, Ariovaldo Lopes. O uso de ferramentas tecnológicas em ambientes de aprendizagem: critérios para avaliação de matérias de ensino em formato digital. Caminhos em linguistica aplicada, Taubaté, v.16, n. 2, jan./jun. 2017. Disponível em: http://periodicos. unitau.br/ojs-2.2/index.php/caminhoslinguistica/article/view/2292/1698. Acesso em: 20 jul. 2017

SIGNORINI, I.; CAVALCANTI, M. C. Língua, linguagem e mediação tecnológica. Trabalhos em Linguistica Aplicada, Campinas, 49(2): 419-440, Jul./Dez. 2010.

USHIODA, Ema. Motivation. In: BURNS, Anne; RICHARDS, Jack C. (org.). The Cambridge Guide to Pedagogy and Practice in Second Language Teaching. New York: Cambridge UniversityPress, 2012.

VYGOTSKY, Lev Semenovitch. O desenvolvimento dos processos psicológicos superiores. São Paulo: Martins Fontes, 1998.

ZACHI, Vanderlei José. Jogos eletrônicos e novos letramentos no ensino de língua inglesa. In: TAKAKI, Nara Hiroko; MACIEL, Ruberval Franco. (org.). Letramentos em terra de Paulo Freire. São Paulo: Pontes Editores, 2017.

YOZO, Ronaldo Yudi K. 100 jogos para grupos: uma abordagem psicodramáticapara empresas, escolas e clínicas. São Paulo: Ágora, 1996. 


\section{Apêndice}

Tabela1 - Instrumento de análise de materiais didáticos com uso de TDIC

\section{IDENTIFICAÇÃO DO MATERIAL}

Título: Charades

Autor(s): ArtGame Studio

Objeto de ensino (tópico/disciplina): Ensino de LI

Público alvo: Nível Intermediário e Avançado de LI

Modalidade de uso: $(\mathbf{X})$ não presencial ( ) híbrido

Suporte: ( ) página da web (X) aplicativo ( ) cd-rom

( ) outro:

Modo de acesso: ( ) log in on-line $\quad(\mathbf{X})$ download

Parte 1: ASPECTOS TÉCNICOS

CRITÉRIOS

Design/layout (caracterização do AVA ou da plataforma)

Comente brevemente: $\mathbf{O}$ aplicativo é de uso simples, apresenta uma aba que ensina a como jogar e é autoexplicativo.

Acessibilidade

a) Cadastro de usuário

( ) com geração de senha própria

$(\mathbf{X})$ acesso integrado

( ) com dados complexos. Explicitar tipos de dados: 
b) Convergência de mídias e suportes

( ) sim () não

Quais? ( ) notebook (X) celular $(\mathbf{X})$ tablet

c) Integração de mídias e suportes

( ) $\operatorname{sim}(\mathbf{X})$ não

d) Seleção/restrição para participação

( ) $\operatorname{sim}(\mathbf{X})$ não

Como? (X) conhecimento prévio

( ) sorteios ou vínculos a produtos/serviços

( ) números de acesso

Suporte

Seçóes de FAQ (Perguntas frequentemente feitas pelos usuários)

( ) sim, com eficiência ( ) sim, com limitaçôes $\quad(\mathbf{X})$ não

Comentários:

b) Tutoriais

(X) sim, com eficiência ( ) sim, com limitaçôes （ ) não

Comentários: A parte How To Play ensina o passo a passo de como jogar.

c) Linguagem acessível

( ) $\operatorname{sim} \quad(\mathbf{X})$ não

Comentários: Algumas palavras requerem um domínio maior da LI

d) Auxílio a pessoas com limitaçóes/ necessidades especiais

( ) $\operatorname{sim} \quad(\mathbf{X})$ não

Comentários: 


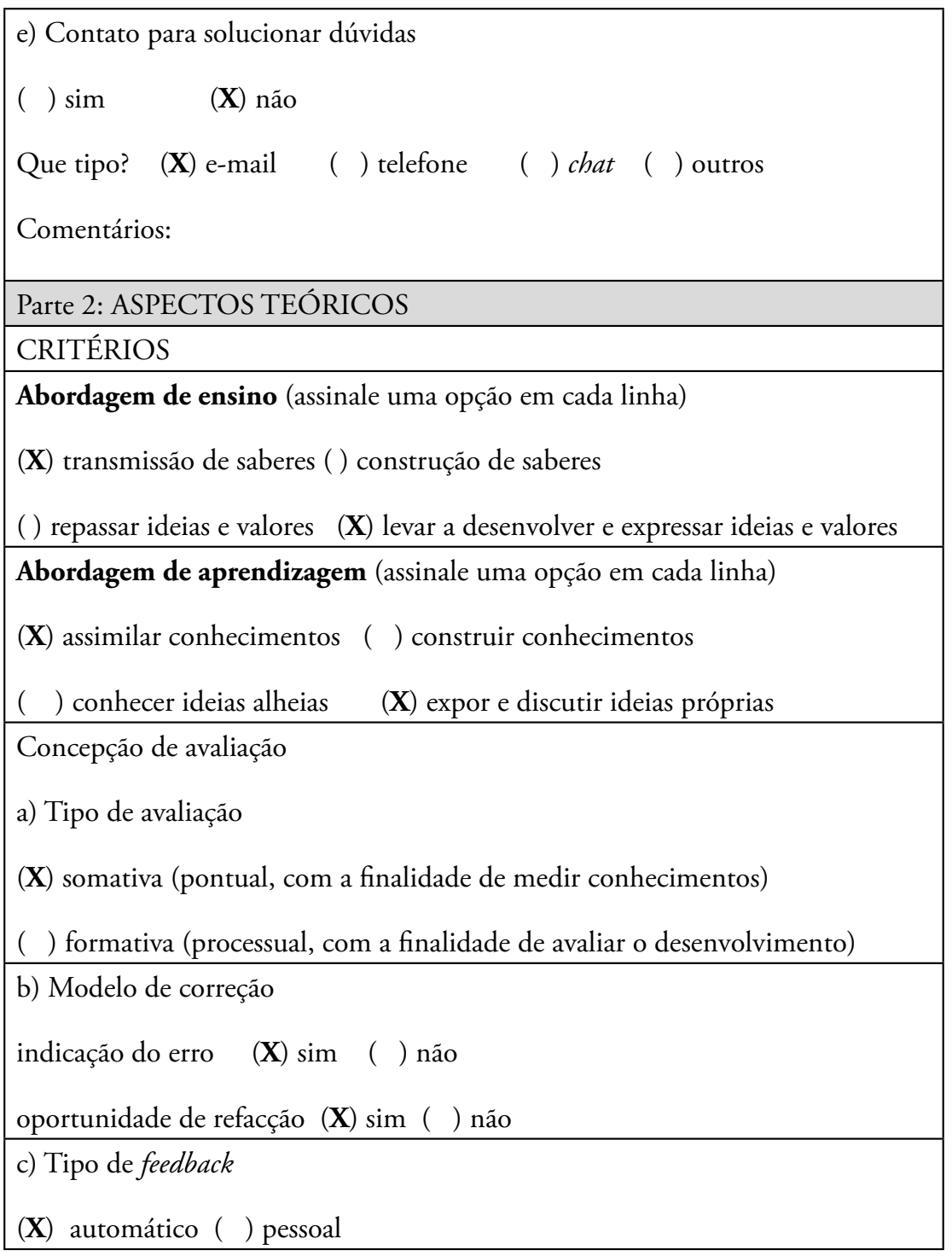




\section{Interação e interatividade}

a) Modelo proposto

(X) interação (entre as pessoas)

(X) interatividade (pessoas com o instrumento/ferramenta)

b) Temporalidade

(X) síncrona $\quad($ ) assíncrona

c) Movimento

(X) endógeno $\quad($ ) exógeno

d) Recursos interacionais

( ) chat ( ) fórum ( ) videoconferência (X) Outro(s): Presencial ( de uma pessoa com outra)

e) Postagens

( ) $\operatorname{sim}(\mathbf{X})$ não

$($ ) endógena $\quad($ ) exógena

Presença de recursos

( ) áudios (X) vídeos ( ) imagens ( ) infográficos $(\mathbf{X})$ jogos ( )

quadros e tabelas $(\mathbf{X})$ outro(s): Escrita, nomes. 


\section{Multimodalidade}

Hiperlinks

(X) $\operatorname{sim} \quad()$ não

Relação entre os conteúdos presentes nos links

(X) não ( ) sim

Direcionamento para navegar entre os links

(X) não ( ) sim

Comentários sobre a natureza dos hiperlinks: Apresenta apenas propagandas com vídeos, que quando clicadas levam a novos aplicativos.

Parte 3: ASPECTOS PRÁTICOS

CRITÉRIOS

Flexibilidade

a) Possibilidade de acessar conteúdos de modo livre

(X) $\operatorname{sim} \quad($ ) não

b) Variedade de opçóes de ferramentas para acessar o conteúdo

(X) $\operatorname{sim} \quad($ ) não 


\section{Engajamento}

a) Progressão no conteúdo

$$
\text { (X) automática por acertos ( ) acesso randômico }
$$

b) incentivo à continuidade de acesso

$$
(\mathbf{X}) \operatorname{sim} \quad(\quad) \text { não }
$$

( ) por pontos ( ) por incentivos ( ) por acertos

( ) por disponibilização de conteúdos extra

( ) por mensagens $(\mathbf{X})$ outro(s): por moedas virtuais que permitem jogar mais.

Comente sobre detalhes relativos ao engajamento. Quanto mais se joga, mais moedas se ganha para jogar sobre outros temas.

\section{Afetividade}

Feedback (resposta avaliativa) após o término de tarefas/etapas

( ) $\operatorname{sim} \quad(\mathbf{X})$ não

Uso de emojis ou ícones próprios para fornecer feedback

( ) $\operatorname{sim} \quad(\mathbf{X})$ não

Comentários fornecidos como feedback

( ) $\operatorname{sim} \quad(\mathbf{X})$ não

( ) automáticos ( ) personalizados

Comente sobre detalhes relativos à afetividade. $\mathbf{A}$ afetividade, nesse aplicativo, está na interaçáo real de participante com participante. 


\section{AVALIAÇÃO GERAL}

Você recomenda o uso desta ferramenta?

(X) $\operatorname{sim} \quad$ ( ) não

Justifique. Pois auxilia a aprendizagem de LI, visto que incentiva os alunos a continuarem jogando e ampliando seus vocabulários de forma divertida.

Fonte: SABOTA; PEREIRA, 2017

Recebido em: 19 set. 2019.

Aceito em: 12 nov. 2019. 